\title{
Introducing a System to Ensure Academic Integrity
}

\author{
Henry M. Spinelli
}

Received: 7 September 2011 / Accepted: 7 September 2011/Published online: 23 September 2011

(C) Springer Science+Business Media, LLC and International Society of Aesthetic Plastic Surgery 2011

The editorial office informs you concerning its use of the iThenticate system. This software is used to prevent plagiarism and ensures that content is original by comparing the manuscript text against a large database of previously published works.

The iThenticate system provides a detailed report including a similarity index that indicates the percentage of matches. A high similarity index does not necessarily constitute plagiarism, but inquiries will be made concerning manuscripts that have a similarity index exceeding a certain threshold. Authors should be prepared to defend their manuscripts in such cases.

Do not take offense if inquiries concerning your manuscript are made because they are the result of a statistical cutoff. Matches may be related only to an author citing his or her own past publications. However, in the rare case of suspected or proven plagiarism, as judged by the editorial office and its staff, the manuscript will be consummately rejected. Further punitive action in cases of repetitive plagiarism may be required and will be instituted on a case by case basis by the editorial office.

Additionally, we note that we are requiring a higher standard for photographs going forward. This includes high picture quality in terms of pixel density, focus, reproducible comparative pre- and postoperative views, magnification, and orientation. This is particularly salient for manuscripts that depend on an aesthetic appreciated by the readers or on improvements or changes from the pre- to the postoperative state of the patient.

We raise these issues in the spirit of further improving the uniformity and quality of this worldwide and inclusive scientific journal. Please feel free to contact the editorial office with any questions or comments.

H. M. Spinelli ( $\square)$

875 5th Ave., New York, NY, USA

e-mail: hms@conmx.net 